\title{
Estimating the Pollutant Loss Rate Based on the Concentration Process and Landscape Unit Interactions: A Case Study of the Dianchi Lake Basin, Yunnan Province, China
}

\section{Minghao Wang}

Chinese Research Academy of Environmental Sciences

\section{Yong Wang}

Chinese Research Academy of Environmental Sciences

Lijie Duan

Tsinghua University

Xiaoyang Liu

TCARE

Haifeng Jia

Tsinghua University

Binghui Zheng ( $\nabla$ zhengbinghui@craes.org.cn )

Chinese Research Academy of Environmental Sciences https://orcid.org/0000-0003-3169-1521

\section{Research Article}

Keywords: Pollutant loss rate, Concentration process, Landscape pattern, Source sink relationship

Posted Date: January 28th, 2022

DOI: https://doi.org/10.21203/rs.3.rs-1132354/v1

License: (c) (1) This work is licensed under a Creative Commons Attribution 4.0 International License.

Read Full License 


\section{Abstract}

The landscape analysis model establishes a quantitative relationship between landscape patterns and pollution processes. The spatial heterogeneity within and between landscapes affects the pollutant transmission process and originates from the superposition effect of terrestrial geographical and morphological characteristics. This study aimed to develop a new method to estimate the pollutant loss rate. From the perspective of the flow process of pollutants entering a water body, the interaction between each landscape unit and adjacent unit during pollutant migration was simulated along the pollutant migration flow path. The role of pollutants affected by external forces in the process of migration could be divided into "promoting" and "hindering." Four indices were proposed to simulate the pollutant loads entering the lake. The linear coefficients between the load of the pollutants chemical oxygen demand $\left(\mathrm{COD}_{\mathrm{Cr}}\right)$, ammoniacal nitrogen $\left(\mathrm{NH}_{3}-\mathrm{N}\right)$, total nitrogen $(\mathrm{TN})$, and total phosphorus (TP) entering the lake and the pollutant load emission weighted by the upstream and downstream confluence ratio index were $0.930,0.835,0.925$, and 0.795 , respectively, and the non-linear variance explanation coefficients were $87.70 \%, 87.50 \%, 87.60 \%$, and $84.70 \%$, respectively. When the surface resistance was integrated into the index as a parameter, the linear and nonlinear correlation coefficients were significantly improved. The linear coefficients were $0.952,0.897,0.919$, and 0.939 , respectively, and the non-linear variance explanations were $99.00 \%, 97.30 \%, 95.10 \%$, and $97.30 \%$, respectively. The spatial distribution of landscape surface resistance reflects the spatial movement trend of pollutants from different sources. The indices characterizing the promoting and hindering effects could be integrated to calculate the loss rate of pollutant load entering the lake from landscape units at different locations in the basin space.

\section{Introduction}

Lake ecosystems play an important role in maintaining regional ecosystem balance, regulating regional climate, supplementing groundwater sources, regulating and storing excess floodwater, and protecting biodiversity and rare species resources (Wang et al., 2021). Moreover, lake ecosystems play a significant role in regional ecological security. The most active social and economic development activities associated with lake systems are typically distributed in the lakeside zone, which is characterized by robust urban-rural construction and represents the development area in lake basins (Wang et al., 2020). Urbanization, industrial development, rapid population growth, and agricultural production activities often lead to an increase in point source and non-point source (NPS) pollutants (Li et al., 2010; Liu et al., 2021b). The issues of territorial ecological space occupation, watershed ecosystem degradation, water quality deterioration, and water surface reduction are becoming increasingly severe, resulting in a significant reduction in the ecological self-regulation and restoration function of watershed ecosystems (Li et al., 2021b). After years of ongoing ecological rectification and administration, the water environment quality of lakes in China continues to improve; however, these improvement trends show significant fluctuation (Wang et al., 2012). As a result, considerable attention has been paid to the control of industrial pollution. However, the improvement of aquatic environment quality by point source 
emissions reduction has encountered a bottleneck. Therefore, it is imperative to explore and establish new methods for systematic and long-term lake management (Efstratiadis and Hadjibiros, 2011).

The correlation between land use and lake water quality changes has a complex spatial and temporal relationship and is also influenced by additional factors (Nielsen et al., 2012). The development and application of landscape ecology provide new perspectives and ideas for environment science research (Post, 1996; Turner and Gardner, 2015). The landscape is a heterogeneous or patchy spatial unit consortium based on land use and is composed of various ecosystem types, representing a composite mosaic that can reflect the comprehensive characteristics of meteorology, climate, ecological processes, and the social economy (Turner, 2005; Wu, 2013). The reclassification of landscape types from the perspective of source and sink is widely recognized by researchers and allows for the clarification of all the functions and properties of land use in the process of pollution mitigation. Moreover, the impact of land use scale and spatial patterns on lake water quality can be determined based on source-sink relationships and used to identify landscape ecosystems susceptible to pollutants in the basin and to control nutrient loss and transmission processes (Chang et al., 2021; Li et al., 2017; Ouyang et al., 2010b).

The NPS pollution exhibited characteristics of multiple governing factors, complex and changeable processes, spatial heterogeneity, and temporal fluctuation (Zou et al., 2020). At present, the basic premise of simulating NPS pollution migration and transmission processes is a constant influence of environmental variables on the process of NPS pollution. However, in the landscape mosaic, which is affected by topography, climate, vegetation conditions, and human activities, the energy flow and logistics state between heterogeneous patches are complex and changeable (Varekar et al., 2021). Moreover, the impact of landscape patterns on lake water quality by changing processes such as material exchange, hydrological processes, and soil erosion between landscapes (Guo et al., 2021; Liu et al., 2011), which are the primary processes involved in the formation and development of watershed pollution (Li et al., 2008). Landscape metrics describe the landscape spatial structure and are the primary methods used to study the impact of landscape patterns on water quality (Xu et al., 2020; Yuan et al., 2015). Ouyang et al. used patch density, edge density, fractal distribution index, and other indicators to express the landscape pattern and determined that various landscape types produced different effects on the nitrogen and phosphorus loads of water systems (Ouyang et al., 2010a). Moreover, Xia et al. reported that water quality is susceptible to changes in landscape patterns, with construction and cultivated land showing a positive correlation with the water pollution index and higher forest coverage correlating to better water quality (Xia et al., 2012). Although landscape metrics are widely used in the analysis of landscape patterns, most researchers consider the type, quantity, and spatial allocation of landscape features as independent variables when analyzing the effects of landscapes on watershed pollution without considering the influence of process mechanisms or the coupling relationship between landscape scale and spatial allocation (Li et al., 2021a). The watershed pollution process is a multiscale and nonlinear spatially explicit process. The conventional landscape metric lacks consideration of scale pattern relationships and process pattern relationships; thus, it is challenging to accurately describe the migration and diffusion processes of watershed pollutants (Winslow, 2014). 
The spatially explicit landscape model typically divides the landscape into different geospatial units according to the landscape function and establishes the relationship between the landscape and the watershed pollution process by describing the characteristics of the units and the ecological flow process between the units (Nobre et al., 2020; Nowosad and Stepinski, 2019). Because this model fully incorporates the characteristics of ecosystems, topography, as well as other aspects, it can be used to accurately describe the energy and material exchange processes between spatial units and simulate the watershed pollution process. Existing research on material migration and energy flow has provided theoretical support and laid a good foundation for establishing ecological process-based models (Sampson et al., 2006). According to the functions of different landscape types in landscape ecology, landscapes can be divided into "source" and "sink." The source landscapes are landscape units (patches) that positively promote the pollution process, whereas the sink landscapes refer to the landscape units (patches) that negatively inhibit or delay the occurrence of the pollution process or the diffusion of pollutants. According to the source-sink theory, the fundamental cause of watershed pollution and pollutant diffusion is the unbalanced profit and loss of nutrients in the landscape unit. When the amount of pollutants generated or received in the landscape unit or patch exceeds its functional threshold, pollutant diffusion and loss will occur. Source-sink landscape models are based on the source-sink landscape function and integrate the coupling relationship between landscape spatial characteristics and ecological processes to establish the internal relationship between landscape variables and watershed pollution processes.

In this study, we aimed to reveal the response law of watershed pollutant load to land use composition and pattern, and determine the influencing factors and response law of lake water quality change. Based on our findings, a lake water quality simulation model was proposed to solve the problem of insufficient expression of spatial processes in the existing models. To achieve these aims, the following procedures were followed: (1) obtaining the land use/cover vector data in the study area using remote sensing data interpretation and analyzing the temporal and spatial differences of land use/cover; (2) calculating the amount of pollutants entering the lake, and analyzing the composition and spatial structure of the pollution source; (3) identifying the response relationship between pollutant emissions and pollutant inflow into the lake; and (4) proposing an estimation method for pollutant load loss rate.

\section{Materials And Methods}

\subsection{Study area}

The lake analyzed in this study was the Dianchi Lake, which is the largest freshwater lake in Yunnan Province, China, and is located in the southwest of Kunming (Fig. 1). Moreover, this lake is the primary source of the Pudu River, a tributary of the Jinsha River, the mainstream of the upper reaches of the Yangtze River. Affected by topography and geological structure, the Dianchi Lake is a typical semi-closed, shallow lake. The Dianchi Lake Basin $\left(102^{\circ} 29-103^{\circ} 01 \mathrm{E}, 24^{\circ} 29-25^{\circ} 28 \mathrm{~N}\right)$ is located in the Jinsha River water system basin, with a drainage area of $2920 \mathrm{~km}^{2}$. The altitude ranges from $1887 \mathrm{~m}$ to $2811 \mathrm{~m}$. 
Diagenetic parent rocks in the Dianchi Lake Basin include sandstone, shale, purple sandstone, limestone, argillaceous sandstone, and basalt. Because of the different diagenetic parent rocks and soil-forming processes that occur in and around the lake, the soil formed is different from the rest of the region. The Dianchi Lake belongs to the Yangtze River basin. The surface and drainage areas of Dianchi Lake are approximately $309 \mathrm{~km}^{2}$ and $2920 \mathrm{~km}^{2}$, respectively. The annual average precipitation in the Dianchi Lake area, most of which occurs in the form of rainfall, is $917.93 \mathrm{~mm}$, and evaporation from the lake is 1426 $\mathrm{mm}$ per annum. The average air temperature was $14.7^{\circ} \mathrm{C}$, and the evaporation from the lake, which amounts to $1409 \mathrm{~mm}$ per year, typically exceeds the rainfall. In 2018, the total resident population of the Dianchi Lake Basin was 4.136 million, including an urban and rural population of 3.832 million and 304 000 , respectively. The GDP of basin settlements is 518.07 billion Yuan.

The river network is an essential fundamental geographic information element and primary hydrological parameter. The whole basin is divided into 25 primary sub-basins and 2932 secondary sub-basins (Fig. 2), using a river network and a digital elevation model (DEM) (downloaded from https://srtm.csi.cgiar.org/srtmdata).

\subsection{Data source}

\subsubsection{Land use and land cover}

The remote sensing images used in this study were Landsat data, which can be downloaded from the Earth Resources Observation and Science (EROS) Center (https://earthexplorer.usgs.gov), and incorporates Landsat-5, Landsat-7, and Landsat-8 data, with an image resolution of $30 \mathrm{~m}$. The Landsat level 2 products released were radiation corrected and geocorrected as well as spatially adjusted to the specified map projection coordinates, which can be used directly as the data source for vector feature extraction. However, image data were preprocessed to improve accuracy, including radiation correction, geometric correction, and fine geometric correction. A DEM was used to correct the parallax caused by terrain fluctuations. The above processes were completed using RPC orthogonalization in the ENVI5.3 toolbox. We used the object-oriented remote sensing image processing algorithm to divide the land use/cover types into five categories, namely cultivated land, forestland, grassland, water, and construction land, as well as 11 subcategories, namely paddy fields, irrigated fields, drylands, forests, shrubby woodlands, mixed forests, grasslands, artificial grasslands, cities, and villages.

\subsubsection{Pollutant load emission}

Pollutant load refers to the amount of pollutants discharged into the environment by the facilities. Pollutant load generation and the amount entering the lake are the most direct external manifestations of the interaction between pollution sources and receiving water bodies. In this study, the pollutant load was calculated using the pollutant load accounting method of the Second National Census of Pollution Sources. The official data and statistics were used in the calculation, mainly including the municipal and competent state departments such as the Ecological Environment Bureau, the Agriculture and Rural 
Bureau, the Housing and Urban-Rural Development Bureau, and the Tourism Bureau. Missing data were obtained from on-site supplementary investigations.

Pollution sources in the basin can be divided into two categories and eight subcategories: point source pollution (industry, urban domestic discharge, and tertiary industry) and non-point source pollution (urban runoff, agricultural runoff, livestock and poultry breeding, rural domestic discharge, and soil erosion).

(1) Pollutant load generation

The pollution load generations of chemical oxygen demand $\left(\mathrm{COD}_{\mathrm{Cr}}\right)$, ammoniacal nitrogen $\left(\mathrm{NH}_{3}-\mathrm{N}\right)$, total nitrogen (TN), and total phosphorus (TP) in the Dianchi Lake Basin in 2018 were 214760.87, 18043.76, 37439.15 , and $3460.93 \mathrm{t}$, respectively (data are listed in Table 1). The process for calculating the pollutant load generation is detailed in Appendix A.

Table 1

Statistics of pollutant generation structure in Dianchi Lake Basin (by source composition)

\begin{tabular}{|c|c|c|c|c|c|}
\hline Pollution source & & $\begin{array}{l}\mathrm{COD}_{\mathrm{Cr}} \\
(\mathrm{t} / \mathrm{a})\end{array}$ & $\begin{array}{l}\mathrm{NH}_{3}-\mathrm{N} \\
(\mathrm{t} / \mathrm{a})\end{array}$ & $\mathrm{TN}(\mathrm{t} / \mathrm{a})$ & $\operatorname{TP}(\mathrm{t} / \mathrm{a})$ \\
\hline \multirow{5}{*}{$\begin{array}{l}\text { Non-point source } \\
\text { pollution }\end{array}$} & agricultural runoff & 5786.34 & 833.96 & 1938.05 & 402.05 \\
\hline & $\begin{array}{l}\text { livestock and poultry } \\
\text { breeding }\end{array}$ & 12518.44 & 650.40 & 3880.87 & 782.75 \\
\hline & rural domestic discharge & 5693.62 & 958.20 & 1528.10 & 83.48 \\
\hline & soil erosion & 1309.03 & 169.91 & 266.17 & 26.10 \\
\hline & urban runoff & 38093.95 & 439.87 & 3817.35 & 135.42 \\
\hline \multirow{3}{*}{$\begin{array}{l}\text { Point source } \\
\text { pollution }\end{array}$} & industry & 1397.58 & 87.11 & 111.66 & 14.35 \\
\hline & $\begin{array}{l}\text { urban domestic } \\
\text { discharge }\end{array}$ & 122033.45 & 14634.19 & 24406.62 & 1851.89 \\
\hline & tertiary industry & 27928.46 & 270.13 & 1490.33 & 164.89 \\
\hline Total & & 214760.87 & 18043.76 & 37439.15 & 3460.93 \\
\hline
\end{tabular}

(2) Pollutant emission reduction

In 2018, twelve sewage treatment plants were constructed in the Dianchi Lake Basin, which were the Kunming, Chenggong County, and Jinning County sewage treatment plants as well as ten wastewater treatment plants around the lake located in the Yu'ni, Baiyu, Gucheng, Laoyu, Luolong, and Luolong rivers as well as Haikou, Baiyu, and Kunyang. According to the operation data of sewage treatment plants and facilities, $\mathrm{COD}_{\mathrm{Cr}}, \mathrm{NH}_{3}-\mathrm{N}, \mathrm{TN}$, and TP were reduced to $168449.79 \mathrm{t}, 12058.90 \mathrm{t}, 21348.49 \mathrm{t}$, and $2734.83 \mathrm{t}$, respectively, by sewage treatment facilities in the Dianchi Lake Basin in 2018. Among them, the reduction 
of point source pollutants was $135810.32 t, 10277.72 \mathrm{t}, 13844.02 \mathrm{t}$, and $1669.87 \mathrm{t}$, respectively; the reduction in agricultural and rural non-point source pollutants was $17381.00 \mathrm{t}, 1702.19 \mathrm{t}, 4909.16 \mathrm{t}$, and $982.02 \mathrm{t}$, respectively; and the reduction of urban NPS pollutants was $15258.48 \mathrm{t}, 78.99 \mathrm{t}, 2595.31 \mathrm{t}$, and $82.93 \mathrm{t}$, respectively.

\section{(3) Structural characteristics of pollutant load emission}

The discharge of pollutants is defined as the amount of pollutant load generated from the removal of pollutants by urban sewage treatment plants and industrial centralized sewage treatment plants for domestic sewage. In 2018, the discharge of the pollutants $\mathrm{COD}_{\mathrm{Cr}}, \mathrm{NH}_{3}-\mathrm{N}, \mathrm{TN}$, and TP in the Dianchi Lake Basin was $46311.08 \mathrm{t}, 5984.86 \mathrm{t}, 16090.66 \mathrm{t}$, and $726.10 \mathrm{t}$, respectively (see Table 2 for specific data). The emissions of pollutants $\mathrm{COD}_{\mathrm{Cr}}, \mathrm{NH}_{3}-\mathrm{N}, \mathrm{TN}$, and TP from point sources accounted for $33.58 \%, 78.76 \%$, $75.60 \%$, and $49.75 \%$, respectively, of the total amount of pollutants.

Table 2

Statistics of pollutant emission structure in Dianchi Lake Basin (by source composition)

\begin{tabular}{|llllll|}
\hline Pollution source & & $\begin{array}{l}\mathrm{COD}_{\mathrm{Cr}} \\
(\mathrm{t} / \mathrm{a})\end{array}$ & $\begin{array}{l}\mathrm{NH}_{3}-\mathrm{N} \\
(\mathrm{t} / \mathrm{a})\end{array}$ & $\mathrm{TN}(\mathrm{t} / \mathrm{a})$ & $\begin{array}{l}\mathrm{TP} \\
(\mathrm{t} / \mathrm{a})\end{array}$ \\
\hline $\begin{array}{l}\text { Non-point source } \\
\text { pollution }\end{array}$ & agricultural runoff & 1596.31 & 253.10 & 983.69 & 90.75 \\
\cline { 2 - 6 } & $\begin{array}{l}\text { livestock and poultry } \\
\text { breeding }\end{array}$ & 3451.36 & 197.02 & 827.02 & 176.66 \\
\cline { 2 - 6 } & rural domestic discharge & 1569.74 & 290.25 & 627.14 & 18.84 \\
\cline { 2 - 6 } & soil erosion & 1309.03 & 169.91 & 266.17 & 26.10 \\
\cline { 2 - 6 } & urban runoff & 22835.47 & 360.88 & 1222.05 & 52.49 \\
\hline Point source pollution & industry & 1397.58 & 87.11 & 111.66 & 14.35 \\
\cline { 2 - 6 } & urban domestic discharge & 11385.01 & 4541.67 & 11384.38 & 317.91 \\
\cline { 2 - 6 } & tertiary industry & 2766.58 & 84.92 & 668.55 & 29.00 \\
\hline Total & & 46311.08 & 5984.86 & 16090.66 & 726.10 \\
\hline
\end{tabular}

From the perspective of spatial distribution (Fig. 3), the northern basin accounted for the highest proportion of pollutant load, and the load proportions of $\mathrm{COD}_{\mathrm{Cr}}, \mathrm{NH}_{3}-\mathrm{N}, \mathrm{TN}$, and TP from this basin were $50.79 \%, 54.04 \%, 52.06 \%$, and $40.16 \%$, respectively. The second largest contributor was the Caohai Basin, and the pollutant load contribution from the western basin was the smallest. Moreover, the load discharges from the Panlong, Baoxiang, Xinyunliang, Haihe, Daqing and Laoyu river basins were higher, mainly in the rivers in the northern basin.

\subsubsection{Pollutant load into the lake}

Pollutant load to a lake or reservoir is a function of the quantities of the polluting materials carried by the inflowing water and the volume of the inflowing water. In this study, pollutant load was calculated using 
the pollutant concentrations and runoff of the main rivers entering the lake. A total of 34 monitoring sections were set up for rivers entering the Dianchi Lake. The monitoring indicators were $\operatorname{COD}_{\mathrm{Cr}}, \mathrm{NH}_{3}-\mathrm{N}$, TN, and TP, and the volume of inflowing river water from January to December 2018 was determined. The river runoff is the primary transport mechanism for pollutants entering the lake in the basin. Based on the tracking investigation of the production and discharge of pollution sources and the loss ways of pollution logistics in the basin, the flux of various pollutants entering the lake was calculated according to the water quantity and quality of the main rivers entering the lake by hydrological stations and monitoring sites.

$$
W=\sum_{i=1}^{12}\left(C_{i} \cdot Q_{i} \cdot T\right)(\text { Equation } 1)
$$

Where, $W$ was the annual load of pollutants load into the lake (t/a), $C_{i}$ was the average concentration of pollutants at the monitoring sites of rivers entering the lake in the $i$ month $(\mathrm{mg} / \mathrm{L})$, and $Q_{i}$ was the average flow at the monitoring sites of rivers entering the lake in the $i$ month $\left(\mathrm{m}^{3} / \mathrm{s}\right) ; T$ was the duration of $i$ th month (s).

The pollutant load of the Dianchi Lake River was calculated from water volume and water quality data for the Dianchi Lake River in 2018 (Fig. 4). The results revealed pollutant loads of $\mathrm{COD}_{\mathrm{Cr}}, \mathrm{NH}_{3}-\mathrm{N}, \mathrm{TN}$, and TP of $22775.87 \mathrm{t}, 1580.70 \mathrm{t}, 6700.14 \mathrm{t}$, and $269.44 \mathrm{t}$, respectively.

\subsection{Assessment Model}

From the perspective of "source-sink" theory, landscape features export NPS pollutants or promote the pollution process in the basin can be regarded as "source" patches, and that can inhibit or slow down the pollution process referred to as "sink" patches (Li et al., 2017). Generally, researchers regard cultivated land, construction land, and unused land in the basin as source landscapes as they promote pollution processes, whereas forestland, grassland, and wetlands, which are characterized by a pollutant interception function, are regarded as sink landscapes ( $\mathrm{Li}$ et al., 2017). The interaction between sourcesink landscapes is through the mechanism of "flow," that is, material transmission. Therefore, when analyzing the impact of landscape patterns on the watershed pollution process, we need to consider the spatial configuration of the landscape and the impact of flow change on the correlation process.

According to the principle of distance decay, the closer the source is to the receptor, the more significant its impact; conversely, the farther away something is, the smaller the impact it has, the lower the spatial proximity effect of geographical variables. Tobler first proposed the geographical law of spatial distance(Tobler, 1970). Later, Li proposed using the concept of "flow" to detect the geographical spatial distance and proximity between two geographical units ( $\mathrm{Li}, 2007)$. The definition of "flow" varies in different scenarios. For watershed pollution, the concept of flow can be used to study the spatial pattern of pollutant transmission and diffusion, and the source landscape exerts an effect on the receiving water body through numerous flows. 


\subsubsection{Migration flow path}

The intensity of the effect of watershed landscape units on receptors can be measured from four aspects: spatial distance, relative elevation, slope (Chen et al., 2008; Wang et al., 2019), and runoff dynamics. It is generally believed that the shorter the distance, the more significant is the contribution. Moreover, the smaller the relative elevation, the shorter the vertical distance, and the greater the impact on the receptor. The greater the slope, the higher the risk of nutrient loss, and the greater the impact on the receptor (Liu et al., 2021a). When the runoff dynamics exceed the sink landscape's interception function threshold, the role of the sink landscape is diminished and can be transformed into a flow (Chen et al., 2003).

The spatial flow path in the basin can be used to describe the potential hydrological process of pollutant transport on the surface of the basin and as well as the migration and diffusion processes of pollutants associated with the hydrological process (Katis et al., 2018). Moreover, the flow path could be calculated according to the geometric elevation and slope, and the confluence path length was used to characterize the action distance between the source and the receptor (Lanni et al., 2012).

The loss of nutrients produced by the source landscape unit is promoted by several dynamic processes. Therefore, when the balance state of nutrients or pollutants is disturbed by the external force of the unit, the migration and diffusion of pollutants will occur, and the cumulative runoff from upstream will be the source of the primary dynamics. A significant correlation was found between the cumulative runoff and cumulative sediment yield and runoff duration. (Xia et al., 2021; Yang et al., 2021).

We calculated the pollutant migration flow path based on the elevation grid map, as shown in Fig. 5a, and the migration direction was determined by the eight-direction (D8) flow model (O'Callaghan and Mark, 1984) ), which contains eight adequate directions on each grid (Fig. 5b). In this model, it is assumed that the pollution flow in a grid flows out of the grid in one direction only; thus, the migration direction is determined according to the relative elevation with the surrounding grid.

Graph theory is an essential mathematical field that originated the Swiss mathematician Leonard Euler's study of the Seven Bridges of Königsberg(Alexanderson and Gerald, 2006). It is a graph model that describes the attributes of objects and their relationship in an abstract way, based on the classification, properties, and characteristics of graphs. The nodes can represent objects, groups, habitats, and their spatial location or attribute information (Fig. 6). The edges can represent the causal relationship, logical relationship, and spatial relationship between objects(Ziolkowska et al., 2014). Theoretically, the processes in basins present prominent graph properties prominently. The spatial location of objects shows the difference of spatial configuration, and the relationship between them can characterize their confluence process. The application of graph theory can simplify the description of the watershed confluence process.

The flow path can only move from one grid to the next along the maximum elevation gradient until it reaches a sink patch, geographical depression, or watershed boundary (outlet) (Fig. 7). The runoff 
direction will be randomly configured when there are two or more directions with the same maximum elevation gradient. Typically, a large number of grids occur in a given area, so the random configuration of this direction can be ignored. The distance from one grid to the next adjacent grid (if any) is the length of the distance along the slope between the centers of the two grids. The calculation of the confluence path was based on the single-flow direction method.

\subsubsection{Interaction between units}

After constructing the pollution flow path, the connection between landscape units was determined through the pollution migration path, as shown in Fig. 8, where the cumulative upstream units of unit $\mathrm{k}$ are represented by the light green filled area, and the cumulative upstream units are the collection of upstream units of all upstream confluence paths passing through unit $\mathrm{k}$. The downstream accumulation units are indicated in yellow, and the downstream accumulation unit is the collection of all downstream units passing through the confluence path of unit $\mathrm{k}$.

\subsubsection{Cumulative dynamic and hindrance ratio index}

The cumulative dynamic and hindrance ratio index was used to measure the pollutant export capacity of the source landscape units under the joint influence of dynamic action and the distance effect. The pollutant generation process of the landscape units under dynamic conditions resulted from cumulative precipitation from the upstream area. When the nutrients or pollutants were disturbed by the external force of the unit and the equilibrium state was disturbed, pollutant migration and diffusion occurred, and cumulative runoff from upstream represented the primary dynamic source. In the process of pollutant migration along the downstream confluence path, the total pollutant loss was affected by the resistance of landscape units, and the migration capability improved with the increase of runoff. The longer the cumulative confluence path upstream of the patch, the greater the runoff dynamics. Moreover, the shorter the downstream path, the lower the confluence loss. Equations 2-7 describe the relationship between the quantities of pollutant into the lake and the spatial characteristics of the landscape units.

Load $=\sum_{k=1}^{K}\left(\frac{\sum_{i=1}^{N_{k}} \alpha_{k i} R C_{k i}}{\sum_{j=1}^{M_{k}} \beta_{k p} \lg \left(F L D_{k p}\right)} \cdot \operatorname{Load}_{k}\right) \pm \varepsilon($ Equation 2)

$\alpha_{k i}=1-C_{k i}($ Equation 3)

$R C_{k i}=\frac{P_{k i}}{Q_{k i}}($ Equation 4) 


$$
\begin{array}{cl}
Q_{k_{i}}=\frac{\left(P_{k i}-0.2 S\right)^{2}}{P_{k i}+0.8 S} & P_{k i}>0.2 S \text { (Equation 5) } \\
Q_{k i}=0 & P_{k i} \leqslant 0.2 S
\end{array}
$$

$\beta_{k p}=C_{k p}($ Equation 6)

$F L D_{k p}=\sum_{q=1}^{P_{p}} F L U_{k p q} \mid P_{p}($ Equation 7$)$

Where, $a_{k i}$ is the dynamic action coefficient of unit $i$ on the upstream path of landscape unit $k . \beta_{k p}$ is the resistance action coefficient of the unit $p$ on the downstream path of landscape unit $k . C_{k i}$ is the vegetation coverage of unit $i$ on the upstream path of landscape unit $k . P_{k i}$ is the precipitation of unit $i$ on the upstream path of landscape unit $k(\mathrm{~mm}) . Q_{k i}$ is the runoff depth of unit $i$ on the upstream path of landscape unit $k(\mathrm{~mm}) . C_{k p}$ is the vegetation coverage of the unit $p$ on the downstream path of landscape unit $k$.

\section{Analysis And Results \\ 3.1 Migration routes}

In this study, the Confluence Length of Downstream (FLD) was used to explain the distance effect of the source-sink space. We defined the FLD as the projection distance on the horizontal plane from the source patches to their destination along the migration route (Fig. 9a). The distribution characteristics of the source patches on the downstream confluence path can be used to explain the risk intensity of the source landscape units owing to the spatial configuration.

The relative spatial position of the landscape units in the basin determines the cumulative runoff. The more upstream confluence is accepted, the greater is the cumulative runoff. The upstream cumulative confluence length (FLU) was used to characterize the cumulative runoff of the landscape units, and was defined as the cumulative projection distance on the horizontal plane of all source patches, using a particular point in the basin as the flow endpoint (Fig. 9b).

\subsection{Linear correlation analysis}

The linear correlation between the pollutant load emission weighted by the upstream and downstream confluence ratio index and the pollutant load discharged into the lake is shown in Fig. 10. The Pearson linear correlation coefficients for $\mathrm{COD}_{\mathrm{Cr}}, \mathrm{NH}_{3}-\mathrm{N}, \mathrm{TN}$, and TP were $0.734,0.832,0.898$, and 0.732 , respectively, which were significant at a 0.01 level. Compared with the unweighted pollutant load emission, the linear correlation coefficient increased by $0.072,0.013,0.009$, and 0.032 . 


\subsection{Non-linear correlation analysis}

When the relationship between variables is unclear, generalized additive models (GAMs) can be used to detect the nonlinear correlation of the overall trend of the two sequences. GAM fits the overall trend rather than analyzing the correlation between point values, which allows us to simulate more complex patterns. GAM was developed to explore the non-linear relationship between pollutant load emission weighted by the cumulative dynamic and hindrance ratio index and the pollutant load discharged into the lake. The results are presented in Table 3. Compared with the unweighted load emissions, the variance explanations of the non-linear relationship increased significantly, and the variance explanations of $\mathrm{COD}_{\mathrm{Cr}}, \mathrm{NH}_{3}-\mathrm{N}$, TN, and TP in the lake increased by $49.40 \%, 20.00 \%, 15.90 \%$, and $29.70 \%$, respectively.

Table 3

Non-linear driving relationship between pollutants entering the lake and pollutant emission weighted by cumulative dynamic barrier index

\begin{tabular}{|llll|}
\hline Pollutant & \multicolumn{2}{l}{ Index weighted Pollutant load emission } & Variation \\
\cline { 2 - 3 } & Variance explanation & $\mathbf{p}$ & \\
\hline $\mathrm{COD}_{\mathrm{Cr}}$ & $87.70 \%$ & $<2.00 \times 10^{-16 * \star \star}$ & $+49.40 \%$ \\
\hline $\mathrm{NH}_{3}-\mathrm{N}$ & $87.50 \%$ & $<2.00 \times 10^{-16 * \star *}$ & $+20.00 \%$ \\
\hline $\mathrm{TN}$ & $87.60 \%$ & $<2.00 \times 10^{-16 * * *}$ & $+15.90 \%$ \\
\hline $\mathrm{TP}$ & $84.70 \%$ & $<2.00 \times 10^{-16 * * *}$ & $+29.70 \%$ \\
\hline
\end{tabular}

Integrating the weighting factors of source-sink spatial distance, relative elevation, slope, runoff generation power, and migration hindrance can characterize the risk intensity of pollutant export caused by the spatial location of the source landscape patches. In this study, we observed a robust positive correlation between the pollutant load emission weighted by spatial allocation and the load into the lake. Moreover, the source landscape patches showed different risk characteristics at different locations in the basin, with shorter distances between flow paths and water bodies resulting in more significant upstream runoff and ultimately a higher risk of pollution. The influence of the confluence path on the pollutant load in the lake is not a simple linear relationship. This is because the discharged pollutants from sources close to the water body have better conditions for entering the lake, and the dynamic conditions of units with high runoff accumulation are advantageous.

\subsection{Response of pollutant load into the lake to surface resistance}

The transformation of pollutants from the source to the receiving water body is a continuous dynamic process involving three aspects: hydrology, soil erosion, and pollutant migration. In the terrestrial area of the basin, these processes are controlled by natural factors inside or between landscape patches, 
including meteorological conditions, soil types, vegetation distribution, and topography. These factors control the characteristics of the underlying surface of the basin and affect the flow state of the substances in the basin. The spatial heterogeneity of natural elements plays a different role in the "source-flow-sink" relationship, affecting the difference in landscape pollution load into the lake.

Seven factors were selected in this study: rainfall erosivity factor $(R)$, soil erodibility factor $(K)$, vegetation cover factor $(\mathrm{VI})$, slope length factor (LS), surface roughness factor (TRI), relative elevation factor (RELE), and terrain wetting index (TWI). The grid layer of each factor was then normalized and reclassified into five grades using the natural breakpoint method. The resistance values were assigned according to the positive and negative correlations between each factor and the NPS pollution process. The resistance values were $1,3,5,7$, and 9 from small to large, and the spatial distribution of the single-factor resistance values is shown in Fig. 11.

Finally, the spatial distribution of multifactor composite resistance in the basin was obtained by the weighted summation of seven resistance factors, as shown in Fig. 12.

The resistance coefficient of the pollutant migration process refers to the obstacles encountered by pollutants during movement within and between landscape units with water flow. The downstream landscape resistance value was used to characterize the resistance of substances in the downstream migration process, and the reciprocal of the upstream landscape resistance value was used to characterize the flow production capacity of the unit. We used landscape resistance as a parameter and reconstructed the cumulative dynamic resistance index (Equations 8-14).

Load $=\sum_{k=1}^{K}\left(\frac{\sum_{i=1}^{N_{k}} \alpha_{k i} R C_{k i}}{\sum_{j=1}^{M_{k}} \beta_{k p} \lg \left(F L D_{k p}\right)} \cdot \operatorname{Load}_{k}\right) \pm \varepsilon($ Equation 8)

$\alpha_{k i}=\frac{1}{R_{k i}}$ (Equation 9)

$R C_{k i}=\frac{P_{k i}}{Q_{k i}}($ Equation 10)

$\begin{array}{cl}Q_{k_{i}}=\frac{\left(P_{k i}-0.2 S\right)^{2}}{P_{k i}+0.8 S} & P_{k i}>0.2 S \\ Q_{k i}=0 & P_{k i} \leqslant 0.2 S\end{array}$ (Equation 11)

$S=25400 / C N-254$ (Equation 12)

$\beta_{k p}=R_{k p}$ (Equation 13) 
$F L D_{k p}=\sum_{q=1}^{P_{p}} F L U_{k p q} \mid P_{p}($ Equation 14)

Where, $R_{k i}$ was the resistance value of unit $i$ on the upstream path of landscape unit $k$, and $R_{k p}$ was the resistance value of unit $p$ on the downstream path of landscape unit $k$.

The linear correlation between the pollution load emissions weighted by the cumulative dynamic barrier index and the pollution load into the lake is shown in Fig. 13. The Pearson's correlation coefficients of the four pollutants were $0.952,0.897,0.919$, and 0.939 , respectively, which were significant at the 0.01 level. Compared with the unweighted pollutant load emissions of $\mathrm{COD}_{\mathrm{Cr}}, \mathrm{NH}_{3}-\mathrm{N}, \mathrm{TN}$, and TP, the correlation coefficients increased by $0.290,0.078,0.030$, and 0.239 , respectively.

The non-linear relationship coefficients between the pollution load emission weighted by the cumulative dynamic barrier index and the pollution load into the lake are listed in Table 4. The analysis results showed that compared with the unweighted load emission, the variance explanation of the non-linear relationship between the pollution load emission and the pollutant load into the lake increased by $50.70 \%$, $19.80 \%, 13.40 \%$, and $12.60 \%$, respectively.

Table 4

Non-linear driving relationship between pollutants entering the lake and pollutant emission weighted by the cumulative dynamic resistance index

\begin{tabular}{|llll|}
\hline Pollutant & \multicolumn{2}{l}{ Index weighted Pollutant load emission } & Variation \\
\cline { 2 - 3 } & Variance explanation & $\mathbf{p}$ & \\
\hline $\mathrm{COD}_{\mathrm{Cr}}$ & $99.00 \%$ & $<2.00 \times 10^{-16 * \star \star}$ & $49.40 \%$ \\
\hline $\mathrm{NH}_{3}-\mathrm{N}$ & $97.30 \%$ & $<2.00 \times 10^{-16 * \star \star}$ & $20.00 \%$ \\
\hline $\mathrm{TN}$ & $95.10 \%$ & $<2.00 \times 10^{-16 * \star \star}$ & $14.00 \%$ \\
\hline $\mathrm{TP}$ & $97.30 \%$ & $<2.00 \times 10^{-16 * * *}$ & $9.60 \%$ \\
\hline
\end{tabular}

\subsection{Spatial characteristics of pollutant load loss rate}

Figure 14 shows the distribution of the pollutant load loss rate in the Dianchi Lake Basin. The same landscape type was affected by the landscape spatial configuration, resulting in different pollution load capacities in the lake. From the analysis results, we observed that a higher loss rate occurred on the banks of the river and around the lake, rather than the linear change along with the buffer distance, consistent with the results of Qian (Qian, 2010). The pollutant load loss rate in the upper reaches of the Panlong River Basin was low, mainly because of the long migration distance of pollutants into the lake, resulting in a significant loss in the process of downstream confluence. The low loss rate in the southern basin was attributed to a small pollutant migration power owing to the short downstream migration path. 
The low pollutant load loss rate was due to insufficient power, even if the downstream migration path was short.

\subsection{Identification of crucial pollution sources}

Figure 15 shows the spatial characteristics of the TN and TP loads into the lake from the basin, which were calculated by multiplying the pollutant load generation with the pollutant load loss rate. The units that contributed significantly to the pollution load into the lake were distributed in the Caohai Basin, the area upstream of the river, and surrounding the lake. The main reason for the significant pollutant load contribution from the Caohai Basin was the dense urban construction occurring in this basin. Urban NPS pollution contributes significantly to pollution loads into lakes and can discharge a large number of pollutants. In an effort to reduce the high pollution rates in the Caohai Basin, numerous polluting facilities in the basin have been shut down, the industrial layout and structure have been optimized, and the industrial pollution sources have been monitored, resulting in a decline in the proportion of point source pollution loads. Conversely, the impact of NPS pollution generated by urban surface runoff on the water environment of Dianchi Lake has become increasingly prominent. Construction land in the basin is mainly concentrated in the urban area of Kunming. The density of the drainage pipe network in the main urban area is approximately $10.22 \mathrm{~km} / \mathrm{km}^{2}$, and the maximum centralized collection rate of urban domestic sewage is $75 \%$. The sewage pipe network system can collect sewage discharged on sunny days; however, the load operation of the sewage treatment plant remains high. Two sets of sewage pipe and rainwater pipe network systems were constructed for the main roads, but there were problems of mixed connection of rainwater and sewage and blocking of outlets along the river in the built-up area. Moreover, the rainwater and sewage diversion rates were low, resulting in a high overload rate of the main road pipe network on rainy days. In addition, the sewage collection facilities built had insufficient sewage carrying capacity. The combined sewage overflow pollution caused by explosive runoff pollutant transportation in the rainy season has become one of the crucial factors affecting the water quality of Dianchi Lake. Although agricultural production produces numerous NPS pollutants in areas far away from the rivers, the generated pollution load does not contribute significantly to the amount of pollutants in the lake due to the loss in the migration process. The pollution load generated in the area around the lake flows into the lake with minimal obstruction and thus contributes more significantly to the total pollution of the lake.

\section{Conclusions}

The pollution transmission process in the Dianchi Lake Basin is affected by the landscape scale and spatial allocation. During the actual transmission process of pollutants, spatial differences within and between landscapes affect the transmission process due to the superposition effect of land hydrology (meteorological conditions) as well as geographical and morphological characteristics (terrain, vegetation cover, soil). Moreover, the base level formed by the superposition of these natural factors can be regarded as the resistance to be overcome in the transmission process of NPS pollution. The smaller 
the cost or amount of work required to overcome resistance, the greater the risk of NPS pollution. At the landscape level, the migration process of pollutants can be seen as the process of pollutants generated by the landscape unit migrating from the source landscape and diffusing to the lake to overcome ground resistance. The resistance elements in the basin are complex, diverse, and spatially dependent. During migration, pollutants are affected by spatially uneven resistance. Therefore, the spatial distribution of the landscape resistance surface can reflect the spatial movement trend of pollutants from different sources. Moreover, the response of pollutant migration to source-sink risk patterns leads to differences in the spatial movement trends.

In this study, we determined that meteorological conditions, soil types, vegetation distribution, and landform types changed the surface roughness and heterogeneity of the basin, affecting the pollution migration process and the ease at which pollutants enter the lake. In particular, the resistance of cultivated land, forestland, and construction land to the surface changed significantly. The increase in construction land flattened the runoff path, enabling the pollutants to easily enter the lake. Farming measures, particularly paddy field farming and management, have increased the difficulty of pollutant migration. Forest vegetation can slow down soil erosion and water and soil loss through interception and leaching of the canopy layer and ground cover interception.

The amount of pollution load entering the lake was determined as the load emission weighted by the pollutant load loss rate, and was affected by the spatial configuration of the pollution source and the interaction of the landscape units. The retardation effect of several landscape units with large "blocking" effects on nutrient diversions, such as grassland and forestland, was related to spatial allocation. Moreover, a shorter distance between the flow path and the river improved the purification effect on the receiving water body.

\section{Declarations}

\section{Data Availability}

The water quality monitoring data, remotesensingdataand land use/cover used in this study can be available from the corresponding author upon reasonable request.

\section{Ethical Approval}

The work did notinvolve Human Participants and/or Animals. To the best of our knowledge and belief,this manuscript has not been considered for publication elsewhere.

\section{Consent to Participate}

All the authors approved to participate.

\section{Consent to Publish}

The authors have reviewed the manuscript and approved it for publication.

\section{Authors Contributions}


Minghao Wang: Methodology, Formal analysis, Data curation, Validation, Data curation.

Yong Wang: Visualization, methodology, Formal analysis, Resources.

Lijie Duan: Formal analysis, Writing-original draft.

Xiaoyang Liu: Investigation, Conceptualization, Writing-review \& editing.

Haifeng Jia: Writing-review \& editing, Supervision.

Binghui Zheng: Project administration, Funding acquisition, Supervision.

\section{Funding}

This work was supported by the Major Science and Technology Program for Water Pollution Control and Treatment in China under grant numbers $2017 Z X 07401004$ and $2018 Z X 07701001$.

\section{Competing Interests}

The authors declare that they have no known competing financial interests or personal relationships that could have appeared to influence the work reported in this paper.

\section{Acknowledgements}

The authors sincerely appreciate the data support by Yunnan Environmental Monitoring Central Station and the remotesensing data obtainedfrom the Earth Resources Observation and Science (EROS) Center (https://earthexplorer.usgs.gov).

\section{References}

1. Alexanderson, Gerald, L., 2006. About the Cover: Euler and the Königsberg Bridges: A Historical View. Bulletin (New Series) of the American Mathematical Society 43, 567-573.

2. Chang, B.X., Wherley, B., Aitkenhead-Peterson, J.A., Mclnnes, K.J., 2021. Effects of urban residential landscape composition on surface runoff generation. Science of the Total Environment 783, 146977.

3. Chen, L.D., Fu, B.J., Xu, J.Y., Gong, J., 2003. Location-weighted landscape contrast index: a scale independent approach for landscape pattern evaluation based on "Source-Sink" ecological processes. Acta Ecologica Sinica.

4. Chen, L.D., Fu, B.J., Zhao, W.W., 2008. Source-sink landscape theory and its ecological significance. Frontiers of Biology in China 3, 131-136.

5. Efstratiadis, A., Hadjibiros, K., 2011. Can an environment-friendly management policy improve the overall performance of an artificial lake? Analysis of a multipurpose dam in Greece. Environmental Science \& Policy 14, 1151-1162. 
6. Guo, L.J., Liu, R.M., Men, C., Wang, Q.R., Miao, Y., Shoaib, M., Wang, Y., Jiao, L., Zhang, Y., 2021. Multiscale spatiotemporal characteristics of landscape patterns, hotspots, and influencing factors for soil erosion. Science of the Total Environment 779, 146474-146474.

7. Katis, I.N., He, P.J.W., Eason, R.W., Sones, C.L., 2018. Improved sensitivity and limit-of-detection of lateral flow devices using spatial constrictions of the flow-path. Biosensors and Bioelectronics 113, 95-100.

8. Lanni, C., Borga, M., Rigon, R., Tarolli, P., 2012. Modelling shallow landslide susceptibility by means of a subsurface flow path connectivity index and estimates of soil depth spatial distribution. Hydrology and Earth System Sciences 16, 3959-3971.

9. Li, N.X., Wang, J., Yin, W., Jia, H.Y., Xu, J.F., Hao, R., Zhong, Z.m., Shi, Z.h., 2021a. Linking water environmental factors and the local watershed landscape to the chlorophyll a concentration in reservoir bays. Science of the Total Environment 758, 143617.

10. Li, Q.L., Wei, C.F., Wang, X.J., et al, 2008. Mechanism and condition of agricultural non-point source pollution. Pedosphere 39, 169-176.

11. Li, S.N., Zhao, X.Q., Pu, J.W., Miao, P.P., Wang, Q., Tan, K., 2021b. Optimize and control territorial spatial functional areas to improve the ecological stability and total environment in karst areas of Southwest China. Land Use Policy 100, 104940.

12. Li, W.F., Cao, Q.W., Lang, K.L., et al, 2017. Linking potential heat source and sink to urban heat island: Heterogeneous effects of landscape pattern on land surface temperature. Science of the Total Environment 586, 457-465.

13. Li, X.W., 2007. The First Law of Geography and Spatial-Temporal Proximity. Chinese Journal of Nature.

14. Li, Y.R., Long, H.L., Liu, Y.S., 2010. Industrial development and land use/cover change and their effects on local environment: a case study of Changshu in eastern coastal China. Frontiers of Environmental Science \& Engineering in China 4, 438-448.

15. Liu, J., Yan, T.Z., Shen, Z.Y., 2021a. Sources, transformations of suspended particulate organic matter and their linkage with landscape patterns in the urbanized Beiyun river Watershed of Beijing, China. Science of the Total Environment 791, 148309-148309.

16. Liu, J.F., Xu, J.J., Zhang, X., et al, 2021b. Nonlinearity and threshold effects of landscape pattern on water quality in a rapidly urbanized headwater watershed in China. Ecological Indicators 124, 107389.

17. Liu, Y., Lv, Y.H., Fu, B.J., 2011. Implication and limitation of landscape metrics in delineating relationship between landscape pattern and soil erosion. Acta Ecologica Sinica 31, 267-275.

18. Nielsen, A., Trolle, D., Søndergaard, M., Lauridsen, T.L., Bjerring, R., Olesen, J.E., Jeppesen, E., 2012. Watershed land use effects on lake water quality in Denmark. Ecological Applications 22, 1187-1200.

19. Nobre, R.L.G., Caliman, A., Cabral, C.R., et al, 2020. Precipitation, landscape properties and land use interactively affect water quality of tropical freshwaters. Science of the Total Environment 716, 137044. 
20. Nowosad, J., Stepinski, T.F., 2019. Information theory as a consistent framework for quantification and classification of landscape patterns. Landscape Ecology 34, 2091-2101.

21. O'Callaghan, J.F., Mark, D.M., 1984. The extraction of drainage networks from digital elevation data. Computer vision, graphics, and image processing 28, 323-344.

22. Ouyang, W., Skidmore, A.K., Toxopeus, A.G., et al, 2010a. Long-term vegetation landscape pattern with non-point source nutrient pollution in upper stream of Yellow River basin. Journal of Hydrology 389, 373-380.

23. Ouyang, W., Skidmore, A.K., Toxopeus, A.G., Hao, F., 2010b. Long-term vegetation landscape pattern with non-point source nutrient pollution in upper stream of Yellow River basin. Journal of Hydrology $389,373-380$.

24. Post, D.A., 1996. Identification of relationships between catchment-scale hydrologic response and landscape attributes. Australian National University, Canberra.

25. Qian, S., 2010. Modeling non-point pollution based on interactions between flow path and landscape units.

26. Sampson, D.A., Waring, R.H., Maier, C.A., et al, 2006. Fertilization effects on forest carbon storage and exchange, and net primary production: A new hybrid process model for stand management. Forest Ecology and Management 221, 91-109.

27. Tobler, W.R., 1970. A computer movie simulating urban growth in the Detroit Region. Economic Geography 46, 234-240.

28. Turner, M.G., Gardner, R.H., 2015. Introduction to Landscape Ecology and Scale, Landscape Ecology in Theory and Practice. Springer, pp. 1-32.

29. Turner, S.J., 2005. Landscape Ecology Concepts, Methods and Applications. Landscape Ecology 20, 1031-1033.

30. Varekar, V., Yadav, V., Karmakar, S., 2021. Rationalization of water quality monitoring locations under spatiotemporal heterogeneity of diffuse pollution using seasonal export coefficient. Journal of Environmental Management 277, 111342.

31. Wang, M.H., Duan, L.J., Wang, J.P., Peng, J.Y., Zheng, B.H., 2020. Determining the width of lake riparian buffer zones for improving water quality base on adjustment of land use structure. Ecological Engineering 158, 106001.

32. Wang, M.H., Liu, X.Y., Yang, B., Fei, Y., Yu, J.J., An, R., Duan, L.J., 2021. Heavy metal contamination in surface sediments from lakes and their surrounding topsoils of China. Environmental Science and Pollution Research 28, 29118-29130.

33. Wang, S., Wang, W., Chen, J., Zhao, L., Zhang, B., Jiang, X., 2019. Geochemical baseline establishment and pollution source determination of heavy metals in lake sediments: A case study in Lihu Lake, China. 657, 978-986.

34. Wang, Z., Zhang, Z.Y., Zhang, J.Q., Zhang, Y.Y., Liu, H.Q., 2012. Large-scale utilization of water hyacinth for nutrient removal in Lake Dianchi in China: The effects on the water quality, macrozoobenthos and zooplankton. Chemosphere 89, 1255-1261. 
35. Winslow, L.A., 2014. Landscape Limnology: Lake morphology and process at the continental scale. Dissertations \& Theses - Gradworks.

36. Wu, J.G., 2013. Landscape sustainability science: ecosystem services and human well-being in changing landscapes. Landscape Ecology 28, 999-1023.

37. Xia, H.J., Kong, W.J., Zhou, G., Sun, O.J., 2021. Impacts of landscape patterns on water-related ecosystem services under natural restoration in Liaohe River Reserve, China. Science of the Total Environment 792, 148290.

38. Xia, L.L., Liu, R.Z., Zao, Y.W., 2012. Correlation analysis of landscape pattern and water quality in baiyangdian watershed. Procedia Environmental Sciences 13, 2188-2196.

39. Xu, S., Li, S.L., Zhong, J., et al, 2020. Spatial scale effects of the variable relationships between landscape pattern and water quality: Example from an agricultural karst river basin, Southwestern China. Agriculture Ecosystems and Environment 300, 106999.

40. Yang, X., Yang, Y., Wan, Y.Y., Wu, R.J., Feng, D.K., Li, K., 2021. Source identification and comprehensive apportionment of the accumulation of soil heavy metals by integrating pollution landscapes, pathways, and receptors. Science of the Total Environment 786, 147436-147436.

41. Yuan, J., Cohen, M.J., Kaplan, D.A., Acharya, S., Larsen, L.G., Nungesser, M.K., 2015. Linking metrics of landscape pattern to hydrological process in a lotic wetland. Landscape Ecology 30, 1893-1912.

42. Ziolkowska, Ostapowicz, Radeloff, VC, Kuemmerle, 2014. Effects of different matrix representations and connectivity measures on habitat network assessments. LANDSCAPE ECOL 2014,29(9), 15511570.

43. Zou, L.L., Liu, Y.S., Wang, Y.S., et al, 2020. Assessment and analysis of agricultural non-point source pollution loads in China: 1978-2017. Journal of Environmental Management 263, 110400.

\section{Figures}




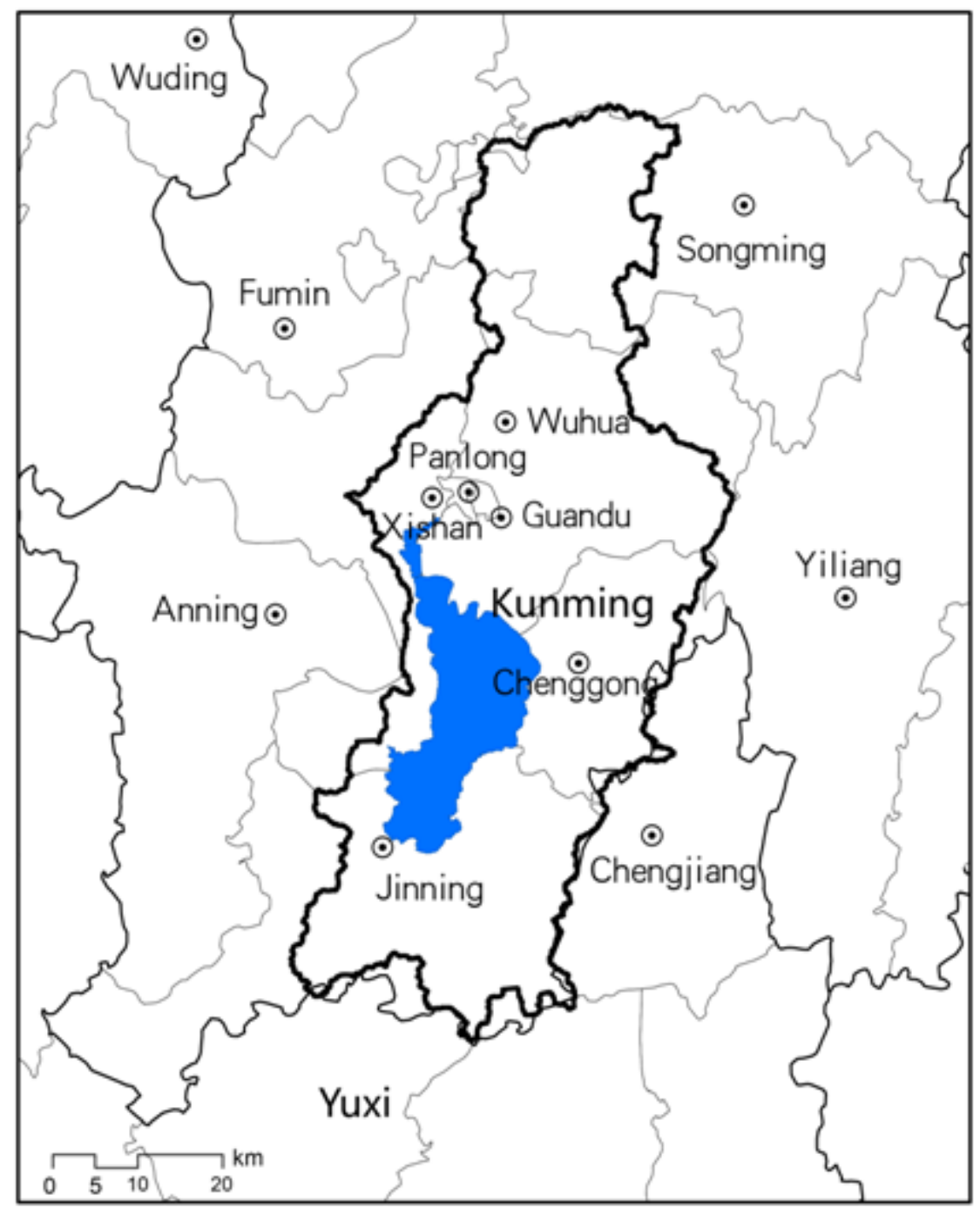

Figure 1

Location of the study area 
Primary sub-basin

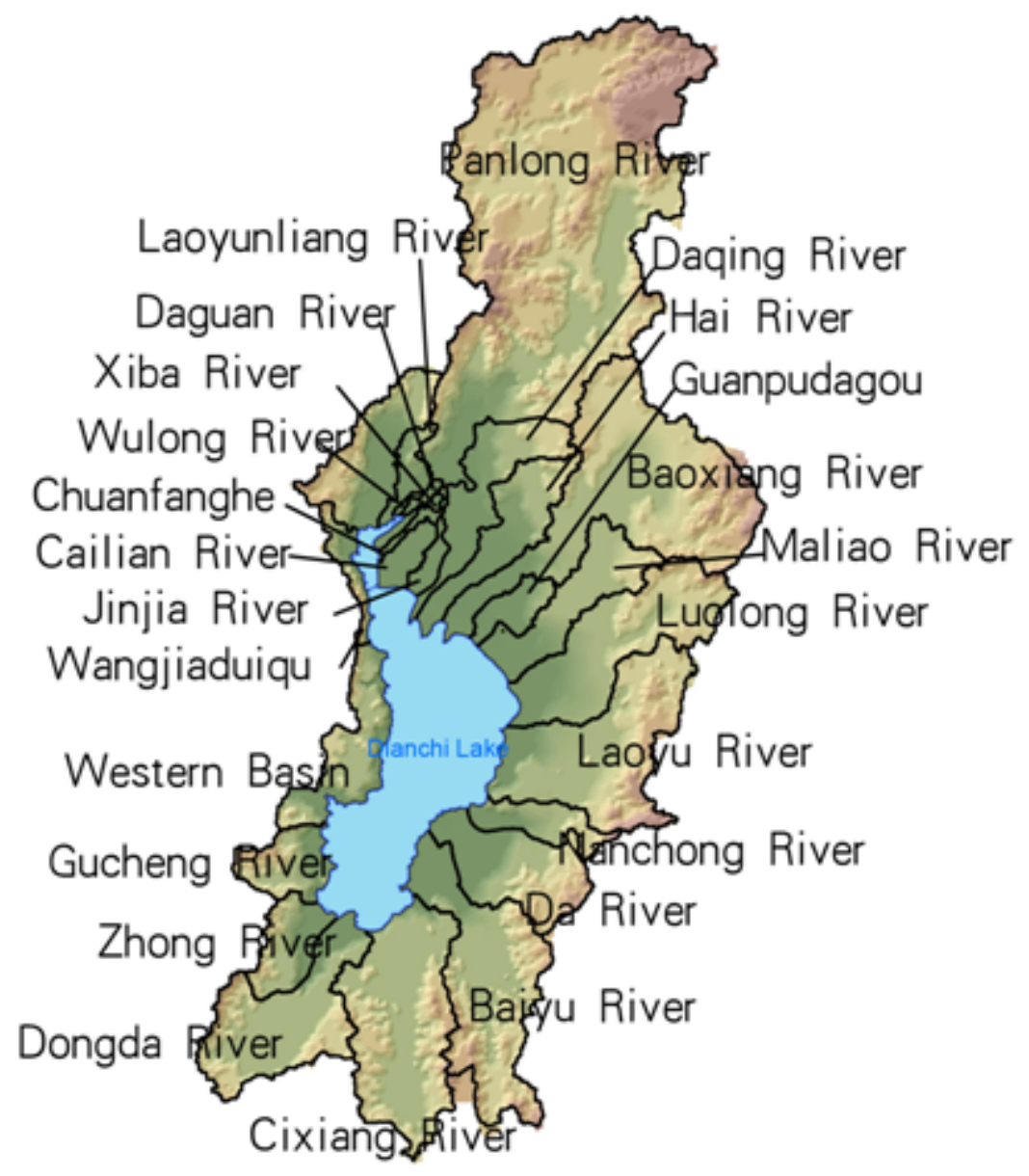

Secondary sub-basin

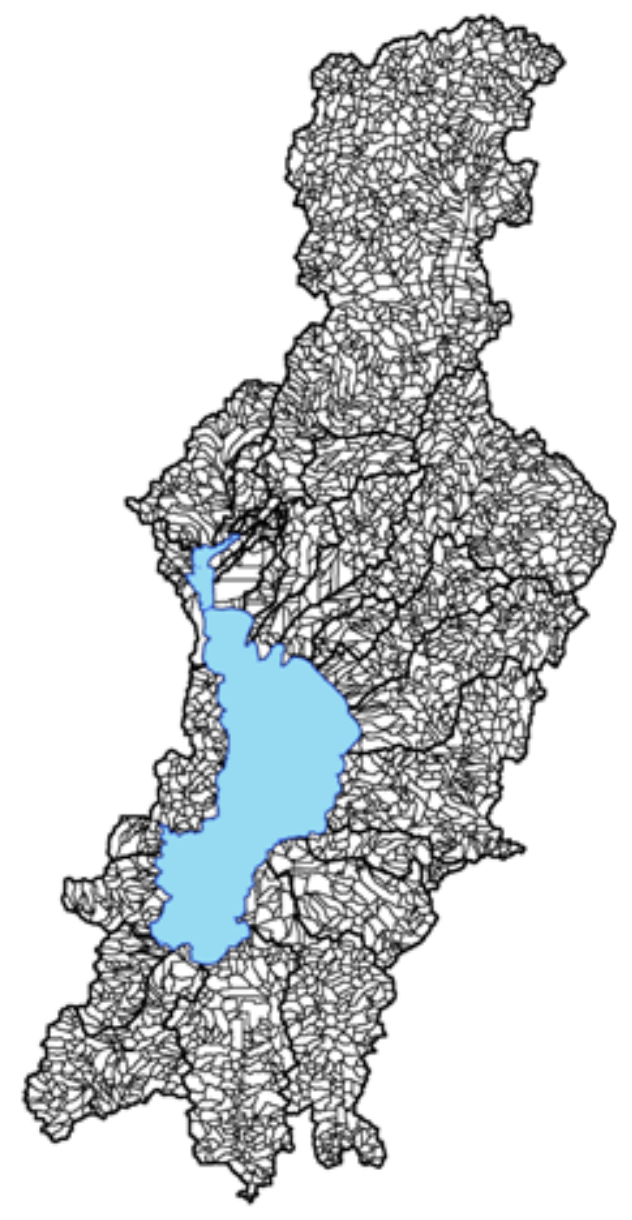

Figure 2

Sub-basins of the study area 

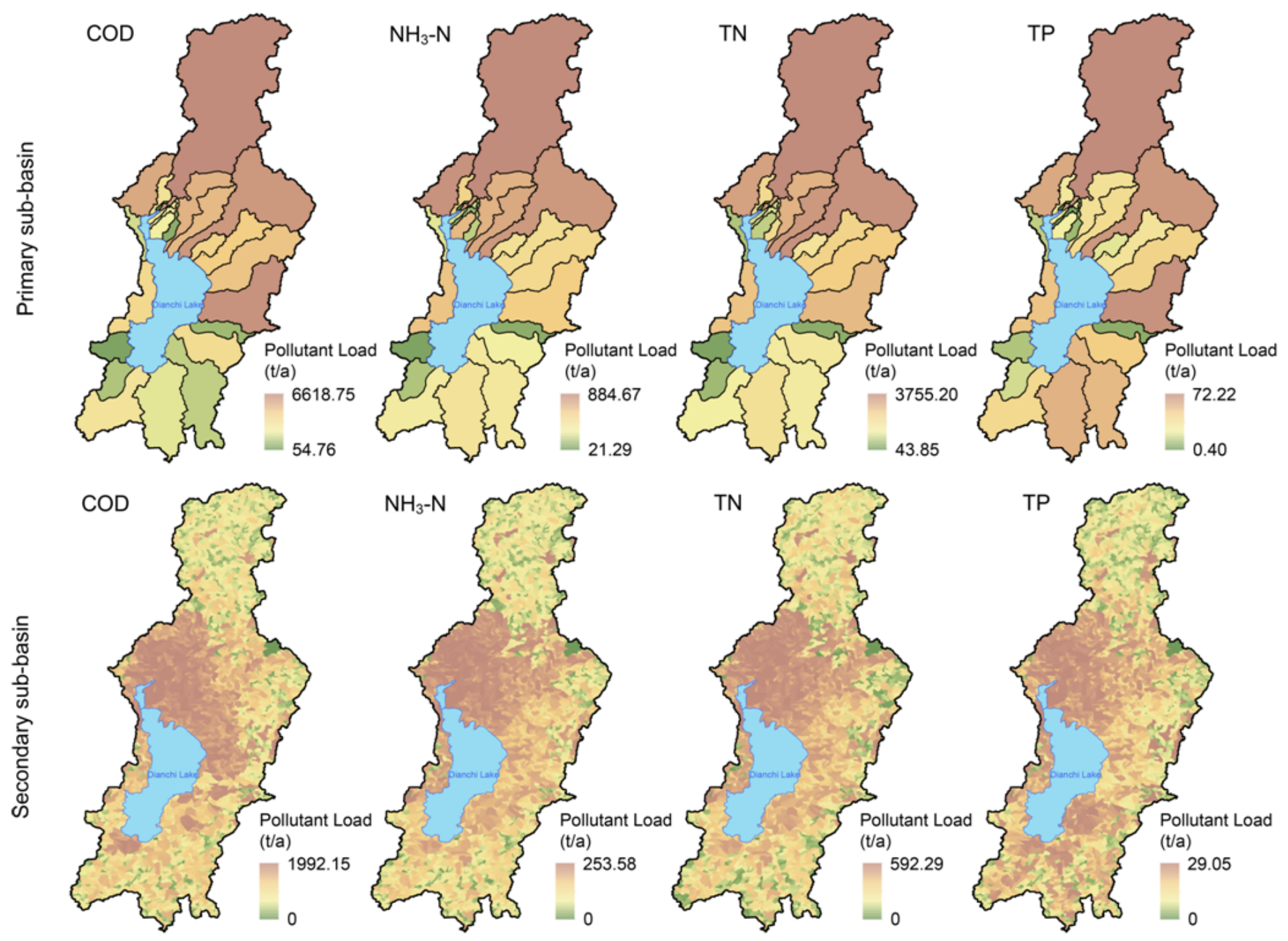

Figure 3

Spatial distribution of pollutant emission in Dianchi Lake Basin 

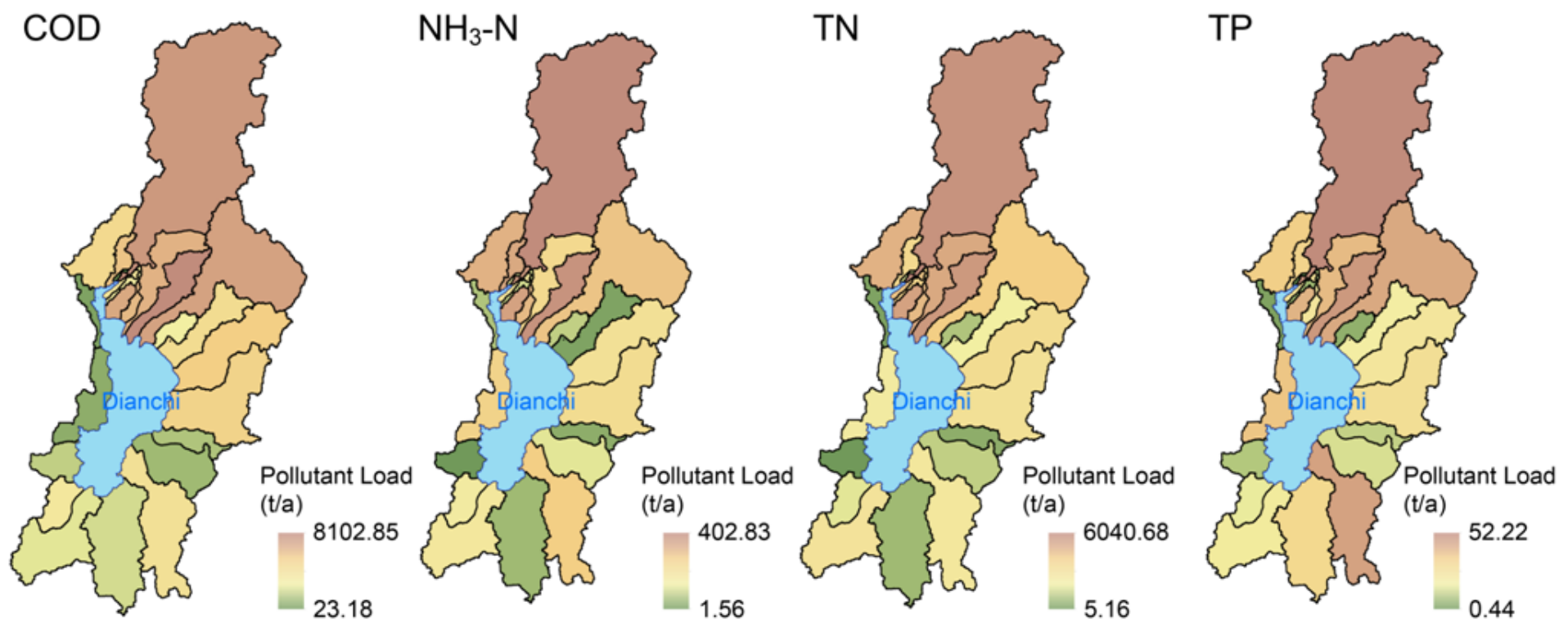

Figure 4

Pollutant load into the Dianchi Lake compiled zonal statistics usingsub-basin feature.

a)

\begin{tabular}{|l|l|l|l|l|l|}
\hline 77 & 71 & 68 & 70 & 57 & 48 \\
\hline 73 & 66 & 55 & 48 & 45 & 49 \\
\hline 68 & 52 & 43 & 36 & 38 & 47 \\
\hline 63 & 57 & 54 & 21 & 30 & 23 \\
\hline 67 & 60 & 46 & 20 & 15 & 18 \\
\hline 73 & 52 & 33 & 11 & 10 & 11 \\
\hline
\end{tabular}

Resistance surface

$\Rightarrow$\begin{tabular}{|c|c|c|c|c|c|}
\hline 2 & 2 & 2 & 4 & 4 & 8 \\
\hline 2 & 2 & 2 & 4 & 4 & 8 \\
\hline 1 & 1 & 2 & 4 & 8 & 4 \\
\hline 128 & 128 & 1 & 2 & 4 & 8 \\
\hline 2 & 2 & 1 & 4 & 4 & 4 \\
\hline 1 & 1 & 1 & 1 & 4 & 16 \\
\hline
\end{tabular}

Direction

b)

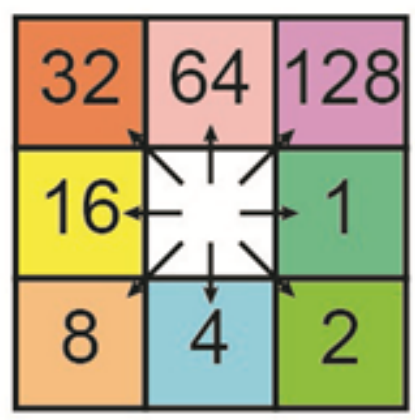

Direction coding 
Figure 5

The direction of migration flow. It is determined by the direction of steepest descent, or maximum drop of resistancesurface, from each cell. The eight directions are coded into eight numbers, whose values range from 1 to 128.For example, if the direction of the steepest drop is to the right of the center cell, its direction would be coded as 1 .

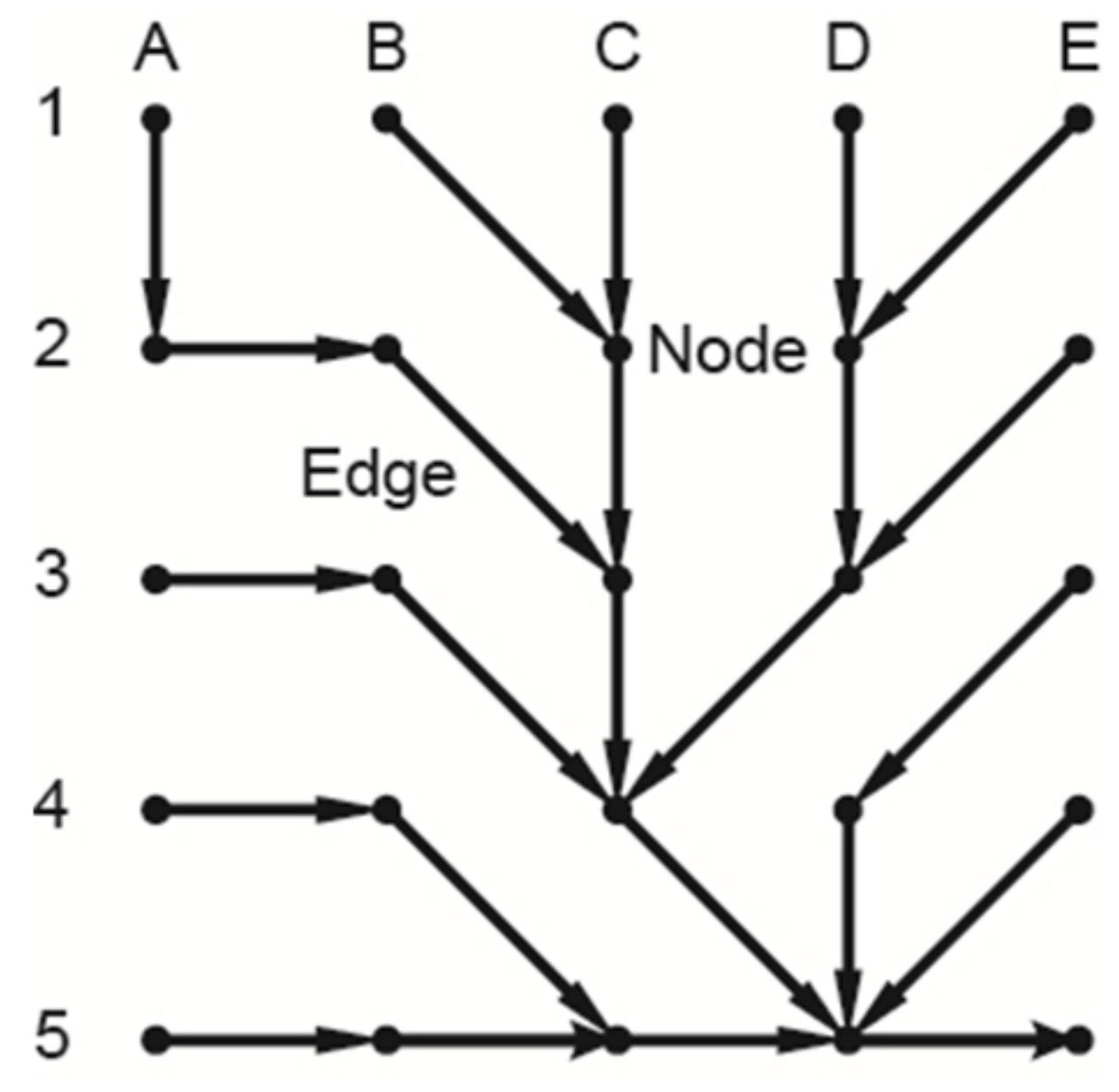

Figure 6

Oriented graph. The points in the figure represent the nodes, and a line with direction connecting each pair of nodes represents edges. 
a)

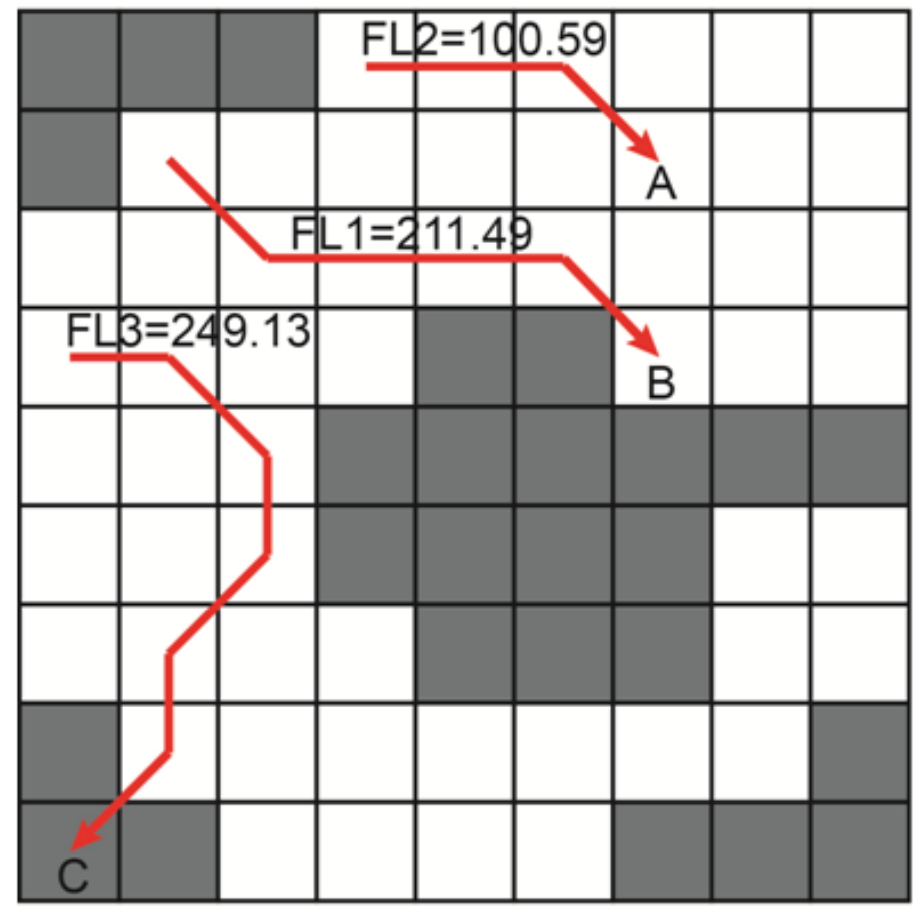

Pollutant migration path b)

\begin{tabular}{|l|l|l|l|l|l|l|l|l|}
\hline 490 & 447 & 473 & 455 & 448 & 437 & 426 & 408 & 398 \\
\hline 498 & 485 & 455 & 465 & 453 & 441 & 400 & 413 & 380 \\
\hline 504 & 500 & 470 & 464 & 452 & 440 & 420 & 412 & 411 \\
\hline 512 & 497 & 485 & 472 & 458 & 445 & 419 & 410 & 375 \\
\hline 524 & 504 & 469 & 474 & 461 & 447 & 435 & 426 & 419 \\
\hline 532 & 508 & 465 & 477 & 463 & 450 & 437 & 429 & 426 \\
\hline 538 & 426 & 493 & 480 & 466 & 451 & 440 & 435 & 432 \\
\hline 544 & 460 & 497 & 482 & 468 & 454 & 447 & 444 & 437 \\
\hline 548 & 524 & 500 & 487 & 475 & 466 & 458 & 450 & 443 \\
\hline
\end{tabular}

Resistance surface

Figure 7

Pollutant migration path between units based on resistance surface

\section{Figure 8}

Up-downstream relationship of unites in the basin 


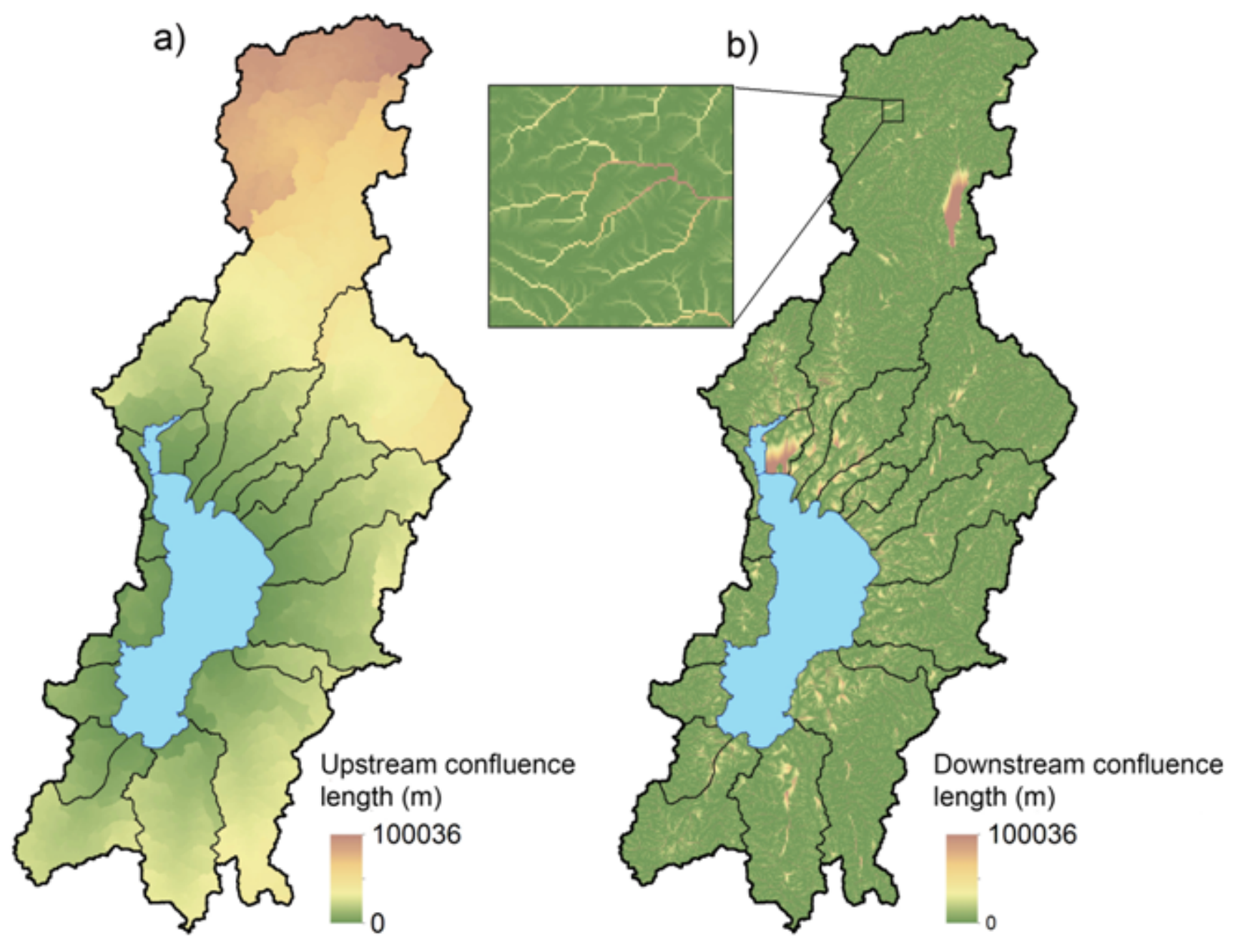

Figure 9

Length of flow concentration path in Dianchi basin, a shows the distribution of upstream confluence length, and $b$ shows the distribution of downstream confluence length. 


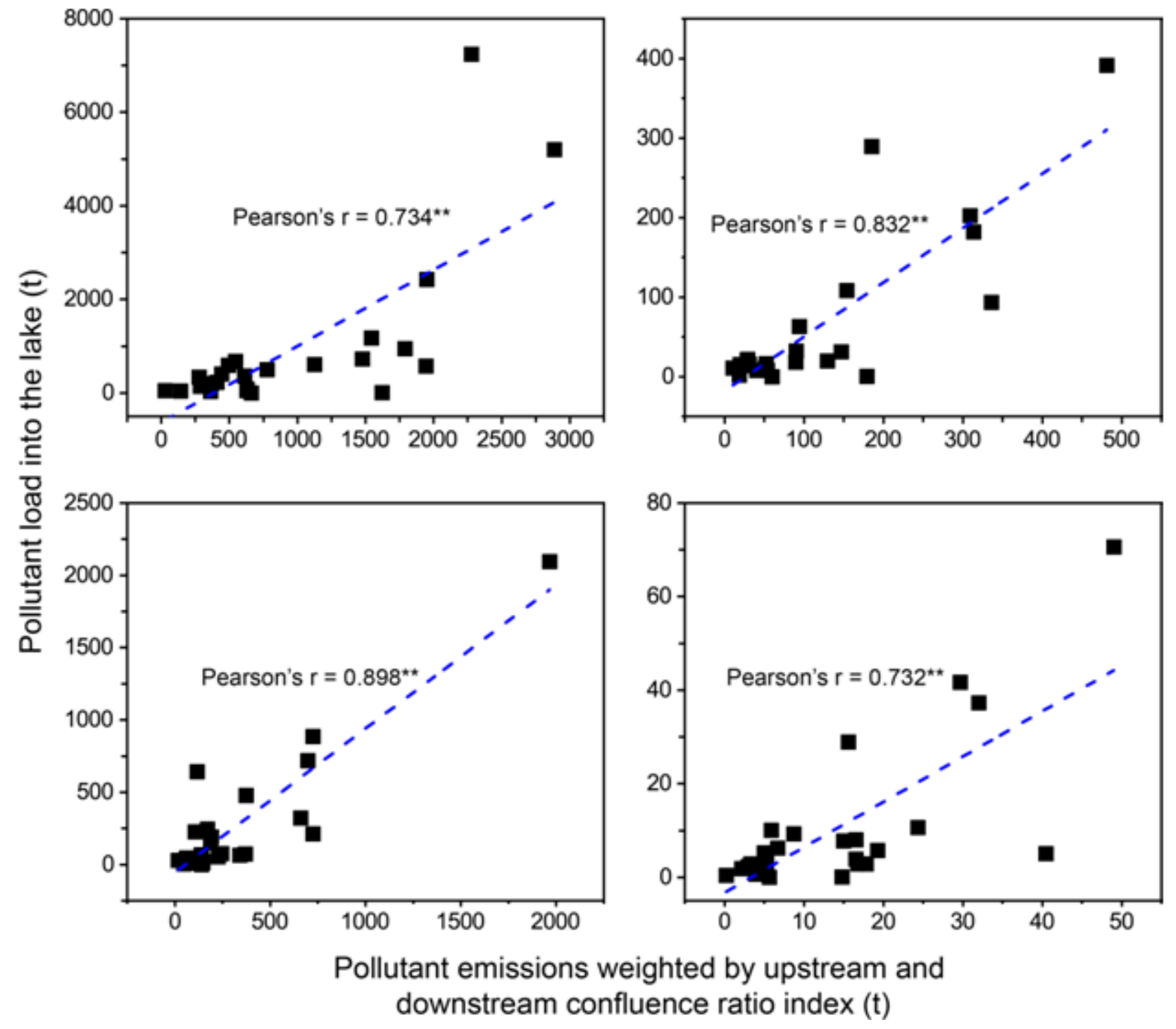

Figure 10

pollutant load emissions and pollutant load inflow entering the lake weighted by upstream and downstream confluence ratio index 

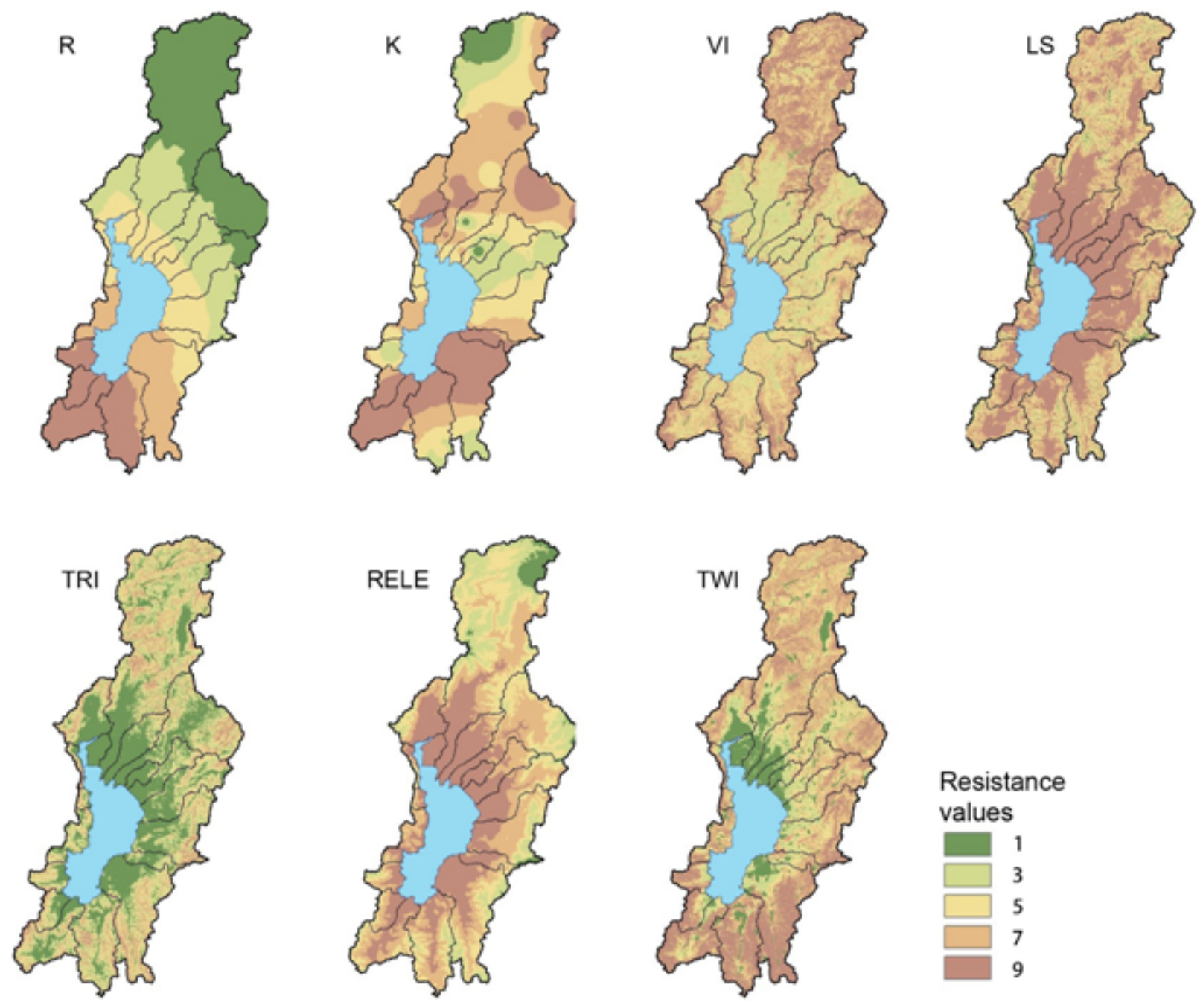

Figure 11

Spatial distribution of single factor resistance value in Dianchi Lake Basin. The values were assigned into $1,3,5,7$, and 9 from small to large.

Figure 12

Spatial distribution of multi-factor composite resistance values. 


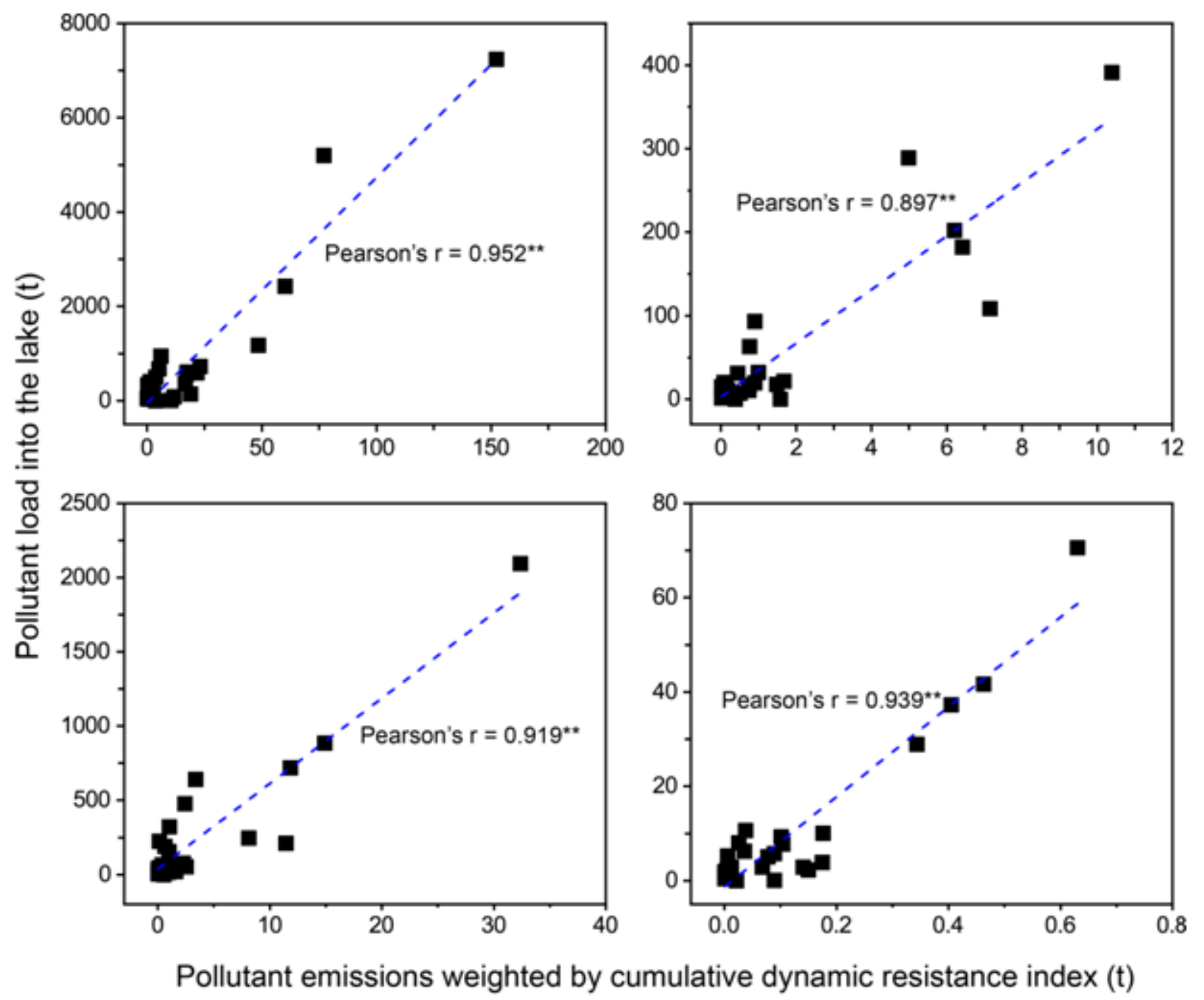

Figure 13

pollutant load emission and pollutant load inflow weighted bycumulative dynamic resistance index 


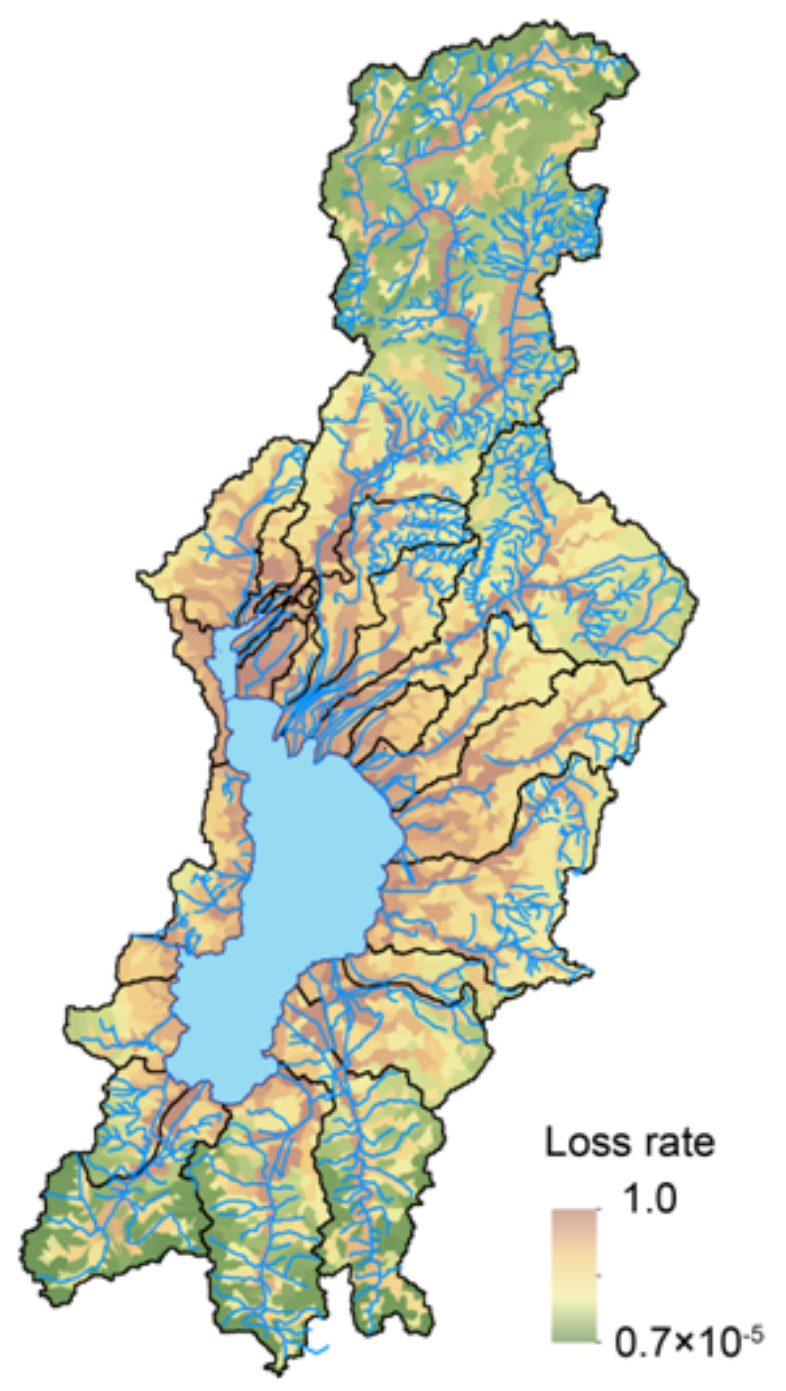

Figure 14

Distribution of pollutant load loss rate.

\section{Figure 15}

Spatial distribution of quantities of pollutant TN and TP into the lakebeing carried by the inflowing water.

\section{Supplementary Files}

This is a list of supplementary files associated with this preprint. Click to download.

- AppendixA.docx 